\section{Vitamin B12 Deficiency with \\ Pseudothrombotic Microangiopathy and \\ Thrombotic Thrombocytopenic Purpura: Similarities and Differences}

Charles Scott Buess, M.D. ${ }^{1}$, Alexander M. Germann, MS-41, Eamon P. Maloney, M.D. ${ }^{2}$, Alaeldin B. Mohammed, M.D. ${ }^{1,3}$

${ }^{1}$ University of Kansas School of Medicine-Wichita,

Department of Internal Medicine, Wichita, KS

${ }^{2}$ University of Nebraska Medical Center, Division of Internal

Medicine, Omaha, NE

${ }^{3}$ Robert J. Dole VA Medical Center, Wichita, KS

Received July 24, 2019; Accepted for publication Nov. 4, 2019; Published online Feb. 28, 2020

\section{INTRODUCTION}

Thrombotic microangiopathy (TMA) encompasses severe conditions caused by microvascular thrombosis including thrombotic thrombocytopenic purpura (TTP) and Shiga toxin-mediated hemolytic uremic syndrome (HUS).' These disorders, associated with high morbidity, share unifying features: microangiopathic hemolytic anemia (MAHA), thrombocytopenia, and organ disfunction. ${ }^{2}$ MAHA describes Coombs-negative hemolysis from intravascular red blood cell fragmentation producing schistocytes on peripheral blood smear. ${ }^{3}$ TTP and HUS are not the only forms of TMA. Cases of metabolism mediated TMA from vitamin B12 deficiency have been reported termed pseudothrombotic microangiopathy (pseudoTMA). ${ }^{4-6}$ Differentiating the etiology of TMA, specifically TTP and vitamin $\mathrm{B} 12$ deficiency is critical as the treatments and prognoses are different. Treatment for TTP requires plasma exchange associated with increased complications and cost as compared to the treatment for vitamin B12 deficiency, which is simply supplementation. ${ }^{7}$ Unnecessary plasma exchange has been reported due to the misdiagnosis of TTP when the actual diagnosis was vitamin B12 deficiency. ${ }^{8}$

The incidence of TTP is less than one case per year per million. ${ }^{9}$ Vitamin B12 deficiency, on the other hand, is far more common. The most frequent serum vitamin B12 cut-off level to diagnose vitamin $\mathrm{B} 12$ deficiency is $150 \mathrm{pmol} / \mathrm{L}(203 \mathrm{pg} / \mathrm{ml})$. Using this serum vitamin $\mathrm{B} 12$ cut-off level, the prevalence of vitamin Bl2 deficiency is $5 \%$ to $15 \%{ }^{10}$ Approximately $2.5 \%$ of vitamin B12 deficiency cases present with hemolytic anemia, thrombocytopenia, and schistocytosis. ${ }^{11}$ Therefore, even though a small proportion of vitamin B12 presents with MAHA, the incidence is higher than TTP. We report a case of a man presenting with profound pancytopenia concerning for TTP that was actually secondary to vitamin B12 deficiency.

\section{CASE REPORT}

A 65-year-old Caucasian male with a history of hepatitis C presented to the emergency room after laboratory evaluation at his primary care provider's office revealed pancytopenia. He endorsed a one-month history of increasing fatigue, interfering with his work as a security guard. He denied a history of blood or coagulation disorders, autoimmune disease, cancer, recent trauma, immobilization, or travel. He initially denied any history of heavy alcohol consumption.

Vital signs were within normal limits. On physical exam, conjunctival pallor was noted. Cardiovascular exam was significant for

\section{KANSAS JOURNAL of MEDICINE}

a 2/6 systolic murmur. He had bilateral $1+$ pitting edema of the lower extremities to the mid-calf with discoloration consistent with venous stasis. His skin showed diffuse ecchymosis of the forearms bilaterally. Table 1 shows lab values on admission.

A peripheral blood smear showed $4 \%$ schistocytes, $2+$ teardrop cells, and hypersegmented neutrophils. Coomb's test was negative. His iron studies and folate levels were within normal limits. Coagulation studies were within normal limits. The patient was transfused with packed red blood cells. A diagnosis of vitamin Bl2 deficiency was made and treatment with intramuscular vitamin B12 initiated. After further questioning, he disclosed that his diet consisted almost exclusively of tomato soup and meatless sandwiches. Since the death of his father and brother earlier in the year, he had increased his alcohol consumption significantly more than he initially indicated, drinking around 8 - 10 beers daily. His ADAMTS13 activity later returned as $100 \%$ activity. He was treated with intramuscular vitamin B12 and follow-up as an outpatient showed complete resolution of his anemia four months later.

Table 1. Lab values on admission.

\begin{tabular}{|l|c|c|}
\hline Lab & Value & Reference Range \\
\hline WBC & $1.6 \mathrm{~K} / \mathrm{cmm}$ & $3.60-11.20$ \\
\hline Hemoglobin & $4.8 \mathrm{~g} / \mathrm{dl}$ & $13.1-16.8$ \\
\hline Hematocrit & $15.0 \%$ & $38.2-48.4$ \\
\hline Platelet count & $34 \mathrm{~K} / \mathrm{cm}$ & $150-400$ \\
\hline Mean corpuscular volume & $121.3 \mathrm{fL}$ & $80.1-98.5$ \\
\hline Reticulocyte count & $3.8 \%$ & $0.50-2.3$ \\
\hline Reticulocyte count, ABS & $0.046 \mathrm{M} / \mathrm{ul}$ & $0.022-0.101$ \\
\hline Total bilirubin & $1.6 \mathrm{mg} / \mathrm{dL}$ & $0.2-1.2$ \\
\hline Direct bilirubin & $0.7 \mathrm{U} / \mathrm{L}$ & $0.0-0.5$ \\
\hline Lactate dehydrogenase & $3449 \mathrm{Units} / \mathrm{L}$ & $125-243$ \\
\hline Creatinine & $0.76 \mathrm{mg} / \mathrm{dL}$ & $0.7-1.3$ \\
\hline Haptoglobin & $<8 \mathrm{mg} / \mathrm{dL}$ & $44-215$ \\
\hline Vitamin B12 & $66 \mathrm{pg} / \mathrm{mL}$ & $213-816$ \\
\hline Parietal cell antibody & $62.5 \mathrm{Unit}$ & $\leq 20.0$ \\
\hline Intrinsic factor Ab & $\mathrm{Negative}$ & Negative \\
\hline
\end{tabular}

\section{DISCUSSION}

Patients showing schistocytosis and thrombocytopenia merit screening for TTP as this disease can be lethal. The PLASMIC score (Table 2) quantifies the likelihood of TTP. ${ }^{12}$ Each criterion scores a point. If the score is in the intermediate to high range (5 to 7 points), a presumptive diagnosis in the appropriate clinical context can be made and is sufficient to initiate treatment. Our patient's PLASMIC score of 5 fell into the intermediate risk. However, his clinical presentation was due solely to vitamin B12 deficiency. Differentiating vitamin B12 deficiency with pseudo-TMA from TTP is of the utmost importance to avoid unnecessary plasma exchange. 
KANSAS JOURNAL of MEDICINE VITAMIN B I 2 DEFICIENCY WITH PSEUDO-TMA

ANDTTP

continued.

As with TTP, vitamin B12 deficiency also can present with MAHA and thrombocytopenia, as seen in our case.

Table 2. PLASMIC score template.

\begin{tabular}{|l|}
\hline PLASMIC Indications (1 point for each indication) \\
\hline Platelet count $<30,000 /$ microL \\
\hline $\begin{array}{l}\text { One or more indicators of hemolysis: Reticulocyte count (percentage }> \\
2.5 \% \text { or haptoglobin undetectable or indirect bilirubin }>2.0 \mathrm{mg} / \mathrm{dL}\end{array}$ \\
\hline No active cancer in the preceding year \\
\hline No history of solid organ or hematopoietic stem cell transplant \\
\hline Mean corpuscular volume $(\mathrm{MCV})<90$ femtoliters \\
\hline International normalized ratio $(\mathrm{INR})<1.5$ \\
\hline Creatinine $<2.0$ mg/dL \\
\hline PLASMIC score: Risk of severe ADAMTSl3 deficiency \\
\hline 0 to 4: Low risk \\
\hline $5:$ Intermediate risk \\
\hline 6 to $7:$ High risk \\
\hline
\end{tabular}

Vitamin Bl2 is necessary for the proper synthesis of deoxyribonucleic acid (DNA) and cell division of hematopoietic cells. ${ }^{13}$ Without adequate stores the nucleated precursors of hematopoietic cells, lines cannot mature, leading to megaloblastic anemia. Neutropenia and thrombocytopenia subsequently may develop. ${ }^{14}$ As the precursor cells are unable to mature, cellular arrest occurs, leading to intramedullary cell death. Lactate dehydrogenase (LDH) enzymes are released during the destruction of nucleated red cells. Therefore, intramedullary hemolysis of immature red blood cells, as seen in vitamin B12 deficiency, can lead to high LDH levels. In fact, LDH levels may be useful in differentiating TTP from vitamin B12 deficiency, as most patients with TTP exhibit LDH levels less than $2500 \mathrm{IU} / \mathrm{L}$, while levels exceeding $2500 \mathrm{IU} / \mathrm{L}$ indicate the possibility of vitamin B12 deficiency. ${ }^{15}$

As bilirubin elevation results from the catabolism of heme, the hemolysis of erythroid precursors, which produce little hemoglobin, results in only a minor increase in bilirubin levels. ${ }^{16}$ In contrast, peripheral hemolysis of mature erythrocytes, which have a high amount of hemoglobin, leads to a much higher indirect bilirubin level. Our patient's LDH levels were much higher relative to his bilirubin levels, more consistent with intramedullary hemolysis of immature erythrocytes secondary to vitamin $\mathrm{B} 12$ deficiency.

ADAMTS13 cleaves von Willebrand factor multimers that are secreted from vascular endothelial cells. ${ }^{17}$ ADAMTS13 deficiency results in unusually large von Willebrand factor multimers, causing platelet thrombi in small vessels with high shear rates, creating schistocytes. Vitamin B12 causes hyperhomocysteinemia, decreased plasma methionine levels, and methylmalonic aciduria. These are associated with platelet activation, generation of reactive oxygen species, endothelial dysfunction, increased tissue factor expression, and coagulation activation. The combination of these factors is thought to lead to peripheral hemolysis, causing schistocytes. Individuals with homozygous or compound heterozygous mutations in a gene encoding the methylmalonic aciduria and homocystinuria type $\mathrm{C}$ protein (MMACHC) are more predisposed to pseudo-TMA as compared to vitamin B12 deficiency without MAHA.

The most helpful parameter in differentiating pseudo-TMA and TTP may be the reticulocyte count. ${ }^{15}$ Those who have pseudo-TMA averaged a $3 \%$ reticulocyte count and TTP averaged $18 \% .^{18}$ Our patient's level of $3.8 \%$ was more consistent with vitamin B12 deficiency. The reticulocyte production index (RPI) makes corrections for both the hematocrit and the reticulocyte lifespan. ${ }^{19}$ Making these corrections determines whether the reticulocytosis truly is increased. In cases of anemia, RPI less than 2 is considered inappropriately low. Our patient's RI was 0.50, indicating a hypoproliferative process.

Both TMA and vitamin B12 deficiency can present with a high $\mathrm{MCV} .{ }^{20}$ In the setting of hemolytic disorders, a high MCV can be due to a high reticulocyte count. Severe macrocytosis with levels greater than $115 \mathrm{fL}$ is associated almost exclusively with megaloblastic anemias, including vitamin B12 deficiency. Our patient's high MCV with a low RI is more consistent with megaloblastic anemia rather than TTP. Of note, ADAMTS13 activity level typically is decreased in TTP; however, due to time limitations, treatment decisions often are initiated prior to obtaining it.

\section{CONCLUSION}

In summary, vitamin B12 deficiency associated with pseudo-TMA can present similarly to TTP with hemolytic anemia, schistocytosis, and thrombocytopenia. Obtaining the correct diagnosis is possible if the clinician understands the clinical differences and differing mechanisms. Vitamin B12 deficiency typically presents with an elevated MCV and relatively low reticulocyte count, whereas TTP may or may not present with an elevated MCV and elevated reticulocyte count. 18,20 MCV greater than $115 \mathrm{fL}$ is consistent with megaloblastic anemias. Vitamin B12 deficiency typically presents with relatively higher levels of LDH and lower levels of bilirubin compared with TMA. ${ }^{15,16}$ MAHA is a feature of both TMA and pseudo-TTP, however, the etiologies of the two differ. ${ }^{17}$

\section{REFERENCES}

1 Kappler S, Ronan-Bentle S, Graham A. Thrombotic microangiopathies (TTP, HUS, HELLP). Hematol Oncol Clin North Am 2017;31(6):1081-1103. PMID: 29078925.

${ }^{2}$ Moake JL. Thrombotic microangiopathies. N Engl J Med 2002; 347(8):589-600. PMID: 12192020.

Brain MC, Dacie JV, Hourihane DO. Microangiopathic haemolytic anaemia: The possible role of vascular lesions in pathogenesis. Br.J Haematol 1962; 8:358-374. PMID: 14014893.

${ }^{4}$ Russo P, Doyon J, Sonsino E, Ogier H, Saudubray JM. A congenital anomaly of vitamin B12 metabolism: A study of three cases. Hum Pathol 1992; 23(5):504-512. PMID: 1568746.

5 Geraghty MT, Perlman EJ, Martin LS, et al. Cobalamin C defect associated with hemolytic-uremic syndrome. J Pediatr 1992; 120(6):934-937. PMID: 1593355

${ }^{6}$ Cornec-Le Gall E, Delmas Y, De Parscau L, et al. Adult-onset eculizumabresistant hemolytic uremic syndrome associated with cobalamin C deficiency. Am J Kidney Dis 2014; 63(1):119-123. PMID: 24210589.

Mokrzycki MH, Kaplan AA. Therapeutic plasma exchange: Complications and management. Am J Kidney Dis 1994; 23(6):817-827. PMID: 8203364.

8 Dalsania CJ, Khemka V, Shum M, Devereux L, Lachant NA. A sheep in wolf's clothing. Am J Med 2008; 121(2):107-109. PMID: 18261496. 
9 Shenkman B, Einav Y. Thrombotic thrombocytopenic purpura and other thrombotic microangiopathic hemolytic anemias: Diagnosis and classification. Autoimmun Rev 2014; 13(4-5):584-586. PMID: 24418304.

${ }^{10}$ Lindenbaum J, Rosenberg IH, Wilson PW, Stabler SP, Allen RH. Prevalence of cobalamin deficiency in the Framingham elderly population. Am J Clin Nutr 1994; 60(1):2-11. PMID: 8017332.

${ }^{11}$ Noël N, Maigné G, Tertian G, et al. Hemolysis and schistocytosis in the emergency department: Consider pseudothrombotic microangiopathy related to vitamin B12 deficiency. QJM 2013; 106(11):1017-1022. PMID: 23842487.

${ }^{12}$ Bendapudi PK, Hurwitz S, Fry A, et al. Derivation and external validation of the PLASMIC score for rapid assessment of adults with thrombotic microangiopathies: A cohort study. Lancet Haematol 2017; 4(4):el57-el64. PMID: 28259520.

${ }^{13}$ Hunt A, Harrington D, Robinson S. Vitamin Bl2 deficiency. BMJ 2014; 349:g5226. PMID: 25189324

${ }^{14}$ Aslinia F, Mazza JJ, Yale SH. Megaloblastic anemia and other causes of macrocytosis. Clin Med Res 2006; 4(3):236-24l. PMID: 16988104.

15 Walter K, Vaughn J, Martin D. Therapeutic dilemma in the management of a patient with the clinical picture of TTP and severe vitamin Bl2 deficiency. BMC Hematol 2015; 15:16. PMID: 26634125.

${ }^{16}$ Garderet L, Maury E, Lagrange M, Najman A, Offenstadt G, Guidet B. Schizocytosis in pernicious anemia mimicking thrombotic thrombocytopenic purpura. Am J Med 2003; 114(5):423-425. PMID: 12714141.

${ }^{17}$ George JN, Nester CM. Syndromes of thrombotic microangiopathy. N Engl J Med 2014; 371(7):654-666. PMID: 25119611.

18 Trubin PA, Edward JA, Hand M. Pseudo-thrombotic thrombocytopenic purpura due to severe vitamin B12 deficiency. J La State Med Soc 2016; 168(6):196-200. PMID: 28045688.

${ }^{19}$ Liesveld JL, Rowe JM, Lichtman MA. Variability of the erythropoietic response in autoimmune hemolytic anemia: Analysis of 109 cases. Blood 1987; 69(3):820-826. PMID: 3814817.

${ }^{20}$ Planche V, Georgin-Lavialle S, Avillach P, et al. Etiologies and diagnostic workup of extreme macrocytosis defined by an erythrocyte mean corpuscular volume over $130^{\circ} \mathrm{fL}$ : A study of 109 patients. Am J Hematol 2014; 89(6):665666. PMID: 24668797.

Keywords: thrombotic microangiopathy, thrombotic thrombocytopenic purpura, microangiopathic hemolytic anemia, vitamin B12 deficiency
KANSAS JOURNAL of MEDICINE

\section{VITAMIN B I 2 DEFICIENCY WITH PSEUDO-TMA}

AND TTP

continued. 